\section{UNIVERSIDADES JESUITAS Y RESPONSABILIDAD SOCIAL: UNA PROPUESTA BASADA EN LA JUSTICIA SOLIDARIA}

\author{
Cristina de la Cruz Ayuso \\ Universidad de Deusto \\ delacruz@deusto.es
}

\section{JESUIT UNIVERSITIES AND SOCIAL RESPONSIBILITY: A PROPOSAL BASED ON SOLIDARITY JUSTICE}

Cómo citar este artículo/Citation: De la Cruz Ayuso, C. (2016). Universidades jesuitas y responsabilidad social: una propuesta basada en la justicia solidaria. Arbor, 192 (782): a363. doi: http://dx.doi.org/10.3989/arbor.2016.782n6008
Copyright: (C) 2016 CSIC. Este es un artículo de acceso abierto distribuido bajo los términos de la licencia Creative Commons Attribution (CC BY) España 3.0.

Recibido: 04 noviembre 2014. Aceptado: 25 agosto 2015.

RESUMEN: El objetivo de este artículo es analizar el concepto de responsabilidad y los procesos para su institucionalización promovidos por las universidades jesuitas subrayando su singularidad y valor frente a otros modelos y estrategias de responsabilidad social universitaria. Ese enfoque de responsabilidad está cimentado en una noción de justicia pensada en términos globales y fundada en la solidaridad, que pone de manifiesto la insuficiencia del enfoque de la responsabilidad como obligación. Su énfasis lo dirige hacia una responsabilidad política compartida que aspira a la transformación de las injusticias estructurales. Este es uno de los rasgos propios de la Identidad y Misión de las universidades jesuitas. En el artículo se identifican los contornos de esa propuesta de responsabilidad encarnada en el ámbito social y se examina su carácter diferenciador frente a otras propuestas impulsadas desde las universidades para definir su compromiso con el entorno.

PALABRAS CLAVE: Universidades jesuitas; responsabilidad social; justicia social; solidaridad descentrada; injusticia estructural.
ABSTRACT: The aim of this article is to analyze the concept of responsibility and its institutionalization processes promoted by the Jesuit universities, emphasizing their uniqueness and value compared to other models and strategies of university social responsibility. This responsibility approach is rooted in a notion of justice conceived in global terms and based on solidarity and that, without rejecting it, highlights the inadequacy of the approach to responsibility as an obligation. Its emphasis is directed towards a shared political responsibility that aspires to transform structural injustices. This is one of the distinctive features of the Identity and Mission of Jesuit universities that define their social status. The article outlines this proposal of responsibility embodied in the social field and examines its distinguishing character compared with other proposals promoted by the universities to define their commitment to the environment.

KEYWORDS: Jesuit universities; social responsibility; social justice; decentralized solidarity; structural injustice. 


\section{RESPONDER DE LAS ESTRUCTURAS QUE ENCARNAN RELACIONES DE INJUSTICIA, UN RASGO PROPIO DE LA NOCIÓN DE RESPONSABILIDAD PROMOVIDA POR LAS UNIVERSIDADES JESUITAS}

La responsabilidad es uno de los conceptos de la Filosofía Política que junto a otros, como el de justicia y solidaridad, ha ocupado un lugar central en la reflexión ética y política de las dos últimas décadas debido a la necesidad de repensar y reenmarcar su significado en un contexto que exige respuestas complejas, globales e interdependientes para la interacción social, y en el que, además, está arraigado un tipo de injusticia para el cual no se ha logrado articular un marco normativo adecuado (de la Cruz Ayuso, 2013). La globalización ha visibilizado una extensa red de interdependencia cimentada en estructuras sólidamente institucionalizadas que crean y reproducen nuevas y viejas relaciones de desigualdad profundamente injustas. Las narrativas de la responsabilidad entendida como culpa, obligación, deber o imputación son variedades de una retórica que, hasta el momento, han servido para mostrar su raigambre en trayectorias y espacios sociales concretos pero que resultan insuficientes en el contexto de la globalización. ¿Quién es responsable, y ante quién, en ese contexto? (Singer, 1993; Arendt, 2007; Young, 2011). Esa pregunta advierte de la necesidad de fortalecer un sentido ampliado de la responsabilidad más allá de la relación de causalidad o el enfoque estrictamente individual, que incorpore su carácter intersubjetivo y proyecte su alcance hacia el mundo ${ }^{1}$. Esta es una idea eminentemente moderna que, tal y como plantea Jonas, deja el mundo en nuestras manos (Jonas, 1995; Muguerza Carpintier, 2002) pero que, al mismo tiempo que abre un campo de múltiples posibilidades para la acción, muestra limitaciones importantes a la hora de afrontar las consecuencias que tiene el despliegue de la responsabilidad política.

Por un lado, en primer lugar, muestra las limitaciones que la práctica de la responsabilidad tiene en sus diferentes escalas macro-meso-micro. La apelación a la responsabilidad en el contexto de la globalización se tiende a plantear desde una escala macro incidiendo en la necesidad de revisar los procesos y los marcos normativos que articulan el orden político, económico y social de ese mundo "global". Esa llamada a la responsabilidad muestra sus debilidades en el momento en el que quedan interpeladas las instituciones llamadas a asumir sus demandas y a operativizar esas normas y procesos desde una lógica de interacción simple (acción-consecuencia) que no responden al carácter global que exigen. Es, efectivamente, a este nivel meso donde afloran las dificultades de las instituciones para afrontar las consecuencias locales que tienen en el corto y medio plazo las decisiones que se toman en el nivel macro, generando desequilibrios intolerables y muchas veces insalvables. Uno de los retos que tiene la institucionalización de ese enfoque de la responsabilidad política está relacionado con su capacidad para articular procesos que incorporen ese enfoque global para intervenir en las estructuras sociales que producen y reproducen las injusticias sociales.

Por otro lado, en segundo lugar, el despliegue de la responsabilidad implica decisiones que necesitan de un tipo de respaldo que no siempre prioriza la búsqueda del bien común y que, por este motivo, termina desdibujando sus contornos en la esfera pública. Las respuestas que exige afrontar transformaciones en estructuras injustas se deben tomar en espacios y a través de procesos que implican a las mismas instituciones que las crean y dentro de unas reglas de juego hegemónicas que terminan naturalizando esas injusticias. Otro de los retos que tiene la institucionalización de ese enfoque de la responsabilidad política está relacionado, por tanto, con su capacidad para articular redes de conexión social entre personas y organizaciones que asuman colectivamente una responsabilidad compartida para luchar contra las injusticias estructurales priorizando, frente a intereses o motivaciones propias, la búsqueda del bien común.

En tercer lugar, ese despliegue de la responsabilidad tiene distintos y diferentes sentidos que la orientan en la práctica hacia direcciones opuestas. No resulta difícil de hecho identificar diferentes tendencias tanto conservadoras como progresistas que inciden, en el caso de las primeras, en la responsabilidad de los individuos para asumir las consecuencias de sus actos o, por el contrario, en el caso de las segundas, en la responsabilidad que todos tenemos frente a desigualdades que dependen del azar social o natural, y por tanto son injustas (Ovejero, 2012). Ambas perspectivas trazan una línea que desplaza la idea de responsabilidad desde un enfoque eminentemente liberal que pone el foco en la independencia y autonomía de las personas, hacia otra idea de la responsabilidad que prioriza aspectos como la interdependencia, la conexión y la relación entre los individuos. Por tanto, otro de los retos que tiene la institucionalización de ese enfoque de la responsabilidad política apunta a la capacidad de liderar procesos de acción colectiva eficaces basados en una solidaridad descentrada en la que personas y organizaciones se vinculan para desarrollar actuaciones en favor de terceros. La motivación para 
generar estos procesos en el seno de instituciones y organizaciones es complejo, como lo es también el armazón sobre el que se construye dicha motivación. En algunos casos puede estar sustentado en una densa carga ideológica. En otros en sólidos liderazgos personales o grupales. En cualquier caso, ese compromiso de actuación a favor de terceros es uno de los rasgos a través de los cuáles esas instituciones definen su lugar social y asientan las bases de su legitimidad.

En cuarto y último lugar, el despliegue de la responsabilidad en un contexto como el de la globalización que pone el foco en las estructuras, apela también al reto de armonizar la tensión entre ese ámbito estructural y las exigencias de inmediatez a las que remite la injusticia, sin asignarles a las iniciativas de responsabilidad un sentido imaginario sino insertándolas en la experiencia de lo social. Las acciones que se desencadenen en nombre de esa responsabilidad deben hacerlo desde una posición "situada"; es decir, desde la propia experiencia de lo real y lo inmediato: explorando, por un lado, las posibilidades que la realidad social proporciona para mostrar algunos gérmenes de transformación y, por otro, analizando el marco de normas y valores de ese contexto social con el fin de que las concepciones de justicia e injusticia que están latentes en él puedan aflorar.

Estas son las claves sobre las que quiero plantear en este artículo la relevancia de las iniciativas de responsabilidad social universitaria (RSU) promovidas por las universidades jesuitas. Estas incorporan un sentido político de la responsabilidad basado en una concepción de la justicia pensada en términos globales y fundada en la solidaridad que, sin rechazarlo, pone de manifiesto la insuficiencia del enfoque de la responsabilidad como obligación. Su énfasis lo dirige hacia una responsabilidad política compartida que aspira a la transformación de las injusticias estructurales. Desde un concepto de responsabilidad como obligación, hay muchas dificultades para identificar y concretar, al mismo tiempo, la injusticia estructural y la forma de eliminarla. Esta concepción de justicia solidaria es uno de los rasgos propios de la Identidad y Misión de las universidades jesuitas que contribuye a definir su lugar social. También es el eje vertebrador de su proyecto universitario que, en la práctica, se concreta y articula en torno a la promoción de estrategias de responsabilización en el ámbito social orientadas a descubrir las múltiples posibilidades que el entorno ofrece para "transformar las estructuras de convivencia que encarnan relaciones injustas" (véase Los Antiguos Alumnos de la Compañía de Jesús y su Responsa- bilidad Social, p. 3). Mi tesis es que la articulación en la práctica de esta concepción de la responsabilidad de las universidades jesuitas, en torno a lo que ha venido a llamarse "responsabilidad social universitaria", aporta elementos para hacer frente a las limitaciones a las que he hecho referencia anteriormente.

De manera general, las universidades han abordado con distinta y desigual motivación y alcance la integración de políticas e iniciativas de responsabilidad social universitaria ante las exigencias de un contexto que las insta, al igual que al resto de instituciones sociales, políticas y económicas, a asumir este enfoque y articular procesos de responsabilización en todos sus ámbitos de actuación. ${ }^{2}$ Los esfuerzos de las universidades jesuitas se sitúan en la actualidad en ese contexto. Esta es una cuestión que no se puede obviar. Sin embargo, un análisis de las distintas estrategias abordadas por las universidades para responder a esta demanda permite visibilizar algunos rasgos propios que caracterizan la particularidad del enfoque de los centros universitarios de la Compañía de Jesús. Esos rasgos ponen de manifiesto un sentido profundo de la idea de justicia social en el que, acorde a su condición y tradición jesuitas, nociones como la responsabilidad, la solidaridad descentrada, el trabajo en red, o la incidencia política adquieren unos contornos muy particulares, concretados en los Decretos de las Congregaciones Generales 32 a la $35^{3}$.

La particular expresión que las respuestas a los desafíos que la promoción de la justicia plantea a los centros del sector universitario de la Compañía es muy diversa y se traduce finalmente en un sinfín de iniciativas que, si bien son muy diferentes entre ellas dependiendo del contexto, región, continente (e incluso de las diferentes culturas institucionales que cada una de ellas tiene), comparten, sin embargo, una muy concreta manera de proyectar su vocación y responsabilidad por la justicia. Todas esas iniciativas están (o podrían estar) integradas dentro de ese concepto de responsabilidad social universitaria como expresión de la forma en la que se concreta en el sector universitario la identidad y misión jesuitas. Estos son los aspectos que desarrollaré en los siguientes tres apartados.

\section{DISTINTOS ENFOQUES, MOTIVACIONES Y ESTRATE- GIAS DE RESPONSABILIDAD SOCIAL UNIVERSITARIA}

El debate sobre el lugar social de la universidad tiene una larga trayectoria que se ha ido construyendo con reflexiones que tratan de mostrar las distintas respuestas de la universidad a los retos que, a lo largo de su dilatada trayectoria, se le han ido presentando en 
cada momento. La novedad del debate actual consiste en que probablemente nunca como hasta ahora ha habido tanta distancia entre lo que se espera que las universidades asuman como parte de su responsabilidad con la sociedad y la respuesta que éstas están dando para responder a esas expectativas. En Julio de 2009, la Conferencia Mundial de la Educación Superior de la UNESCO en París resaltaba su papel tan fundamental en esta tarea de definición y construcción de la sociedad.

"La sociedad ha conferido a sus instituciones educativas más responsabilidad social que nunca. Las expectativas son altas: ahora esperamos que el sistema educativo no sólo capacite a nuestros niños y jóvenes, sino además que nos libre de la pobreza y nos ponga en el camino de la paz y el desarrollo sostenible. ¿'Podrán nuestras instituciones de enseñanza superior cumplir con sus crecientes responsabilidades en el ámbito del desarrollo socioeconómico? ¿Cuál es el alcance razonable de las responsabilidades sociales que deben asignarse a la educación superior y cómo podremos garantizar que todos los países, lo mismo del Norte que del Sur, estén en condiciones de cumplirlas? ¿Acaso el cumplimiento de estas responsabilidades necesitará de una reformulación radical del pensamiento y el modelo de educación superior dominantes? La universidad debe ir a la par de los objetivos más vastos del desarrollo sostenible, la reducción de la pobreza, la paz y los derechos humanos. En una época de crisis medioambiental y económica, ¿por qué deberían las universidades ser cada vez más útiles con miras a influir en el desarrollo socioeconómico y cómo podrían hacerlo?" (Conferencia Mundial sobre la Educación Superior - 2009).

Desde la mitad del siglo $X X$ se viene insistiendo en la idea de que estamos viviendo una transición de la sociedad industrial a la sociedad del conocimiento. Esta transición afecta de manera radical a la universidad, principal productora del mismo hasta el momento, obligándola, entre otras cosas, a adecuar sus tradicionales funciones docentes e investigadoras a un contexto en el que se le exige también el desarrollo de la capacidad de innovación y la adaptación a un mercado del conocimiento cada vez más competitivo. Esta transición ha sido uno de los principales factores de cambio que obligan a repensar el papel de la universidad en la sociedad.

No ha sido el único. El fenómeno de la globalización es otro de los factores que, como señalaba anteriormente, ha transformado nuestro mundo. Algunos de los cambios que ha traído consigo han sido y serán muy determinantes para la universidad: la educación virtual y a distancia; nuevos modelos y métodos de enseñanza y aprendizaje; la formación directa y aplicada en contextos de realidad específicos, etc. son algunos de los rasgos que visibilizan ese cambio en las universidades. El uso de las tecnologías, la mayor diversificación de títulos y diplomas universitarios, la vertiginosa velocidad de la internacionalización de la enseñanza, la importancia de la educación permanente a lo largo de la vida, etc. son también elementos nucleares relacionados con la calidad, el acceso, la diversidad, la financiación, y la autonomía de las instituciones de Educación Superior.

Todo esto, además, coincide en el tiempo con un estancamiento general del gasto público en Educación que afecta notablemente, entre otras cosas, al modelo de gobernanza de las universidades e incluso, en algunos casos, a su propia autonomía. Los cambios -se dice- exigen mayor especialización y profesionalidad en el ámbito de la gestión, desarrollar una visión de la Universidad distinta a la tradicional, reorganizar las reglas de representatividad, funcionamiento y de toma de decisiones, diferenciar entre las responsabilidades de gestión y las responsabilidades académicas en el gobierno de las universidades, adoptar principios y mecanismos de funcionamiento de transparencia y buen gobierno, e impulsar la cultura de innovación en la comunidad universitaria. Estos cambios inciden en el significado mismo de la Educación Superior, en sus funciones y atribuciones, e imponen también nuevos modelos de gobernanza de las universidades que afectan y han transformado sus tradicionales lógicas de funcionamiento.

La universidad ha reaccionado ante la necesidad de tener que ir transformando paulatinamente sus estructuras de gestión, formación e investigación para adaptarse a ese contexto. La misma pregunta por la responsabilidad social de las instituciones de la Educación Superior es una pregunta que constata que la universidad es consciente de ese proceso de cambio. Y las respuestas que está dando son manifestación de su interés por formar parte activa de ese proceso y de los ámbitos donde se están decidiendo las líneas básicas de actuación de la Educación Superior en las próximas décadas.

No obstante, es preciso señalar que, siendo ese el escenario donde la responsabilidad social universitaria va cobrando relevancia en la última década en la Educación Superior, las universidades han reaccionado de manera distinta y desigual a las exigencias de impulsar políticas o estrategias para su integración en el ámbito universitario. 


\section{a. Estrategias de responsabilidad social orientadas a la} mejora del gobierno y la gestión de las universidades

Por un lado, se han promovido iniciativas que sitúan a la "responsabilidad social" como una herramienta cuyo objetivo es ayudar a mejorar en algunos aspectos la gestión y el gobierno de las universidades. Teniendo en cuenta las características específicas que definen la misión y, por tanto, los distintos ámbitos de actividad de las universidades, este enfoque, en realidad, poco se distingue del que se aplica en el ámbito empresarial. Las herramientas o metodologías de mejora continua en las que se sustentan buena parte de ellas están pensadas para que una universidad pueda dialogar consigo misma, integrar sus diferentes áreas, funciones y personas, y poner el foco en la información institucional que se recopila, en cómo se utiliza dicha información y para qué; en las metas y estrategias de largo plazo y en cómo se organiza la propia institución para realizarlas. La transparencia y la rendición de cuentas, a través de memorias de responsabilidad social o sostenibilidad, son los principales objetivos que hay detrás de algunas iniciativas de Responsabilidad Social Universitaria que siguen este enfoque.

\section{b. Estrategias de responsabilidad social orientadas a la proyección social de la universidad}

Existen otras iniciativas que relacionan la responsabilidad social universitaria con todo el área de "acción social" de la universidad, desde un enfoque cuya razón de ser se sustenta en el argumento de que la universidad es "responsable" de devolver a la sociedad aquello que ella misma le ha posibilitado. El contenido de la responsabilidad se entiende, en este caso, en términos de "deuda con la sociedad". Son innumerables las experiencias de responsabilidad social que se promueven en las universidades que tienen como objetivo precisamente poner en valor aquellos elementos que conforman su agenda social, y que son capaces de generar motivación, implicación y mucho dinamismo en la comunidad universitaria. Muchas de estas iniciativas "sociales" tienen un impacto positivo muy importante y son manifestación del compromiso social de la universidad. Iniciativas de voluntariado, participación social, aprendizaje-servicio, proyectos sociales, política de extensión universitaria, programas de formación permanente, etc. junto con otras, relacionadas con el desarrollo de la carrera estudiantil en la Universidad (sistema de ayudas al estudio, equiparación de oportunidades, formación para el empleo, etc.), son algunos de los ejemplos que podemos encontrar en este enfoque de proyección social.

\section{c. Estrategias de responsabilidad social como expre-} sión de la identidad de la universidad

Existen, en tercer lugar, otras iniciativas de responsabilidad social universitaria que son expresión de la identidad propia de la universidad. Lo que ella hace está profundamente motivado por lo que es. Estas estrategias de RSU se asientan sobre la base de un modelo que identifica a las universidades como espacios de frontera cuya misión debe ser la promoción de la justicia social. Este es el sentido que mejor refleja las distintas estrategias de responsabilidad promovidas desde las universidades jesuitas, en el que la conexión de las mismas con su identidad y misión es uno de los rasgos que la definen y diferencian de los restantes enfoques.

Adolfo Nicolás distingue dos aproximaciones en la noción de la responsabilidad que permite entender el enfoque propio que la responsabilidad social adquiere en su aplicación al contexto universitario jesuita: por un lado, está el sentido de la responsabilidad entendida como "rendición de cuentas" (al que hacíamos referencia anteriormente) y, por otro, el sentido de la responsabilidad entendida como "prestar atención y cuidado" (véase Los Antiguos Alumnos de la Compañía de Jesús y su Responsabilidad Social, p. 2) que alinea a la responsabilidad con la solidaridad.

La tradición ignaciana ofrece una perspectiva de la "responsabilidad con los demás seres humanos (con los semejantes y los diferentes) y con la creación en una lógica de amor y gratitud", más que del deber, la obligación o la "accountability". Sin restar importancia a ésta, Adolfo Nicolás propone que "además de tener como base esta dinámica que nos pide responder ante otros por lo que se nos ha confiado y mantener una transparencia total en el ejercicio de nuestro proceder, nos situemos en la dinámica de la gratitud o del agradecimiento, en fin, del reconocimiento de los bienes recibidos" (véase Los Antiguos Alumnos de la Compañía de Jesús y su Responsabilidad Social, p. 2). Hacerse responsable del mundo no es aprobarlo tal como es, sino asumirlo conscientemente porque es. El Padre Arrupe señaló que la misión de la Compañía siempre ha sido formar agentes de cambio en la sociedad y en la Iglesia, para renovar y transformar las estructuras de convivencia que encarnan relaciones injustas. La promoción de la justicia, educar en el compromiso social, o según las palabras del P. Kolbenvach, formar hombres y mujeres competentes, conscientes, compasivos y comprometidos, son respuesta a ese enfoque de la responsabilidad-agradecimiento al que hace referencia el P. Nicolás (véase Los Antiguos Alumnos de la Compañía de Jesús y su Responsabilidad Social, 2013). 


\section{UN ENFOQUE DE LA RESPONSABILIDAD BASADO EN LA JUSTICIA SOLIDARIA}

En este artículo defiendo el carácter distintivo de este último enfoque de responsabilidad promovido por las universidades jesuitas argumentando que ésta es una noción de justicia pensada en términos globales y fundada en la solidaridad. Su énfasis lo dirigen hacia una responsabilidad política compartida que aspira a la transformación de las injusticias estructurales. Este es un enfoque propio que incide el ámbito universitario jesuita pero que, al mismo tiempo, lo desborda ya que está imbricado en el corazón de la misión de la Compañía. Es único entre las universidades precisamente por el carácter jesuita que las define. Pero no es exclusivo únicamente de las obras del sector universitario de la Compañía, sino del conjunto de todas ellas.

Defiendo además que este enfoque de la responsabilidad, así entendido, permitiría superar algunas de las limitaciones a las que se enfrenta una noción de la responsabilidad como obligación en un contexto como el de la globalización y un problema como el de la injusticia estructural en el que es muy difícil determinar no solo quiénes son los culpables sino también quiénes son sus responsables. Existen injusticias provocadas por actos claramente individuales y existen injusticias provocadas por una pluralidad de acciones de difícil imputación. No sirve el mismo sentido de la responsabilidad para las primeras que para las segundas ya que éstas no tienen que ver con agravios con interacción individual. Es preciso ahondar en la naturaleza y el alcance que exige responder a las segundas desde un concepto de responsabilidad ampliada, vinculada a su carácter político, y analizar lo que supone en la práctica para una universidad que lo toma de referencia para impulsar su política de responsabilidad social universitaria.

Aunque en la parte final señalaré brevemente algunos de los rasgos en los que este sentido de la responsabilidad se especifica en distintos ámbitos de docencia, investigación y proyección social, el objetivo principal es subrayar, más allá de su concreción práctica y de la evaluación que se pueda hacer de sus prácticas y resultados, el valor que en sí mismo tiene ese planteamiento en este momento en el que "no se puede prescindir de las universidades para responder a los desafíos de la injusticia" (Kolvenbach, 2009) y en el que es preciso articular visiones que permitan "repolitizar" esa respuesta.

La Congregación General 32 (CG 32) introdujo la promoción de la justicia como una exigencia de la mi- sión de la Compañía de Jesús. Servicio de la fe y promoción de la justicia quedaban consagrados así como los dos aspectos nucleares de la misión, llamados a hacerse presentes en la diversidad de las Obras de la Compañía. Este aspecto venía a recoger una dilatada historia sobre el compromiso de la Compañía con la sociedad. Se ha señalado que una de las características del concepto de justicia social "jesuita" es su ambigüedad y que es precisamente esa ambigüedad la que realza al término, aunque de hecho dificulte el análisis crítico sobre los modos en los que es promocionada (Greene, 2012). Sin embargo desde el prisma de la "injusticia estructural", ese carácter ambiguo y abstracto adquiere un rostro real y cercano. Precisamente el Decreto de la CG 32 señalaba la opción preferencial por los pobres como un elemento nuclear en la misión y el compromiso por la transformación de las estructuras económicas políticas y sociales injustas. La CG 33 confirmó esta opción por los pobres y la necesidad de trabajar en la transformación de las actitudes y tendencias sociales, desde la noción de "amistad". La amistad política es un concepto que, en el marco de la CG33, aúna dialécticamente amor y justicia. Es definida como la afirmación y reconocimiento comunitario tanto de los valores existentes en los vínculos y estructuras sociales, como de la participación del bien común correspondiente a los individuos y a los grupos. Su práxis en la vida pública, cívica y política está relacionada con un profundo compromiso por la justicia con los pobres y el bien común, e implica interés, compromiso y responsabilidad por las personas concretas y por las condiciones en que esas personas viven.

La CG 34 insistió en la necesidad de transformar las estructuras socioculturales ya que están en la base de las políticas y económicas. La transformación debe ser cultural. Las comunidades de solidaridad aparecen, también en el decreto de la CG34, como instrumentos para promover la solidaridad y desafiar de manera significativa las estructuras sociales injustas. Hay injusticia estructural cuando determinados grupos son susceptibles de caer en determinadas vulnerabilidades por carecer de los medios necesarios y suficientes para poder desarrollar sus capacidades, cuando sus acciones son injustamente obstaculizadas y sufren la amenaza de privaciones, mientras que otros obtienen beneficios significativos. La injusticia estructural se produce sin intencionalidad clara y directa, y sólo en contadas ocasiones la causa un solo individuo singular, puesto que es el resultado inconsciente de acciones habituales y costumbres de mucha gente (Young, 2011). La promoción de la justicia, frente a estas realidades de opresión, va más allá por tanto de la mera 
obligación y exige un compromiso de carácter relacional (Greene, 2012) que queda vinculado con la solidaridad. No se trata de rechazar o reemplazar un sentido de la responsabilidad por otro, sino constatar que el que está basado en obligaciones no es suficiente para responder a esas injusticias estructurales globales. Ese carácter relacional es un elemento de referencia en los textos ignacianos acerca de la justicia. La relación con el otro y un sentido de la solidaridad basado en la idea de "amistad política" son sus pilares: un vínculo frágil pero rico de acción colectiva entre personas e instituciones implicadas en prácticas de solidaridad, que deciden estar juntos para sostener el mismo proyecto de justicia social y tratar de cambiar los procesos sociales que producen injusticias.

La acción de transformar se dirige a modificar la forma en que terceros más poderosos tratan a los pobres, cuando ese trato es injusto. Es la dimensión más propiamente política de nuestra acción social, porque se propone cambiar las estructuras sociales que posibilitan y reproducen la injusticia, combatir las ideas que legitiman tales estructuras, encontrar alternativas a las instituciones que las expresan, modificar las correlaciones de fuerzas sociales y políticas que las construyen y mantienen, organizar a las víctimas injustamente empobrecidas, conciencias y ofrecer vías de compromiso a quienes permanecen al margen, etc. (González Fabre, 2012).

Esta idea de la justicia solidaria apela directamente a un tipo de responsabilidad política que se pregunta por las formas de organización que son necesarias en las instituciones para tener una acción significativa y en su capacidad de influir en los procesos estructurales. Una tarea fundamental que debe hacernos pensar en el ámbito de influencia propio de las universidades y en la capacidad transformadora de su agencia social. Todo ello está relacionado con sus propias condiciones estructurales y organizativas para articular procesos de acción colectiva en torno a sus comunidades de solidaridad.

La CG 35 confirmó nuevamente la misión recogida en la CG32 incorporando un énfasis en el compromiso de cuidar de la creación. Allí también se insiste en que la justicia debe de comprenderse dentro de un marco relacional, de alianzas, que conlleva compromisos más allá de las relaciones contractuales (Álvarez, 2014). Este enfoque de responsabilidad política supone una posibilidad realista de hacer viable las aspiraciones de justicia solidaria. Nos permite pensarlas en el marco de comunidades de solidaridad interconectadas y definirlas en el marco de instituciones concretas, como es el caso de la universidad. Permite proyectar grados y tipos de responsabilidad distintos, exigibles en función de la posición social que tenemos en esas estructuras o en base al vínculo que queramos establecer para sostener un mismo proyecto de justicia social. En cualquier caso, las universidades jesuitas quedan interpeladas para hacerlo realidad a través de algunos retos y tareas fundamentales que deben asumir desde el terreno de la acción.

Por un lado, deben ser capaces de articular procesos que incorporen ese enfoque global para intervenir en las estructuras sociales que producen y reproducen las injusticias sociales. Eso exige capacidad de acción a escala global y formas organizativas en red muy concretas que la favorezcan y permitan una construcción social densa para sostener un mismo proyecto de justicia social. Esto obliga a descentrarse y a construir otras lógicas de poder en las que la Universidad ni es la única ni es la principal institución en la promoción de ese proyecto.

Por otro lado, deben ser capaces de generar procesos de motivación y agregación que conecte a personas y organizaciones que asuman colectivamente una responsabilidad compartida para luchar contra las injusticias estructurales, priorizando frente a intereses o motivaciones propias, la búsqueda del bien común. La actual coyuntura de las universidades da cuenta de yugos institucionales que pueden llegar a bloquear este objetivo.

También deben ser capaces de liderar procesos de acción colectiva eficaces basados en una solidaridad descentrada en la que personas y organizaciones se vinculan para desarrollar actuaciones en favor de terceros. Esto exige que ellas mismas estén motivadas en torno a ese objetivo, lo cual no siempre es fácil en un contexto en el que las demandas a la universidad son no sólo mayores sino distintas, y muchas veces contrarias, a ese enfoque de responsabilidad política.

Finalmente, deben ser capaces de armonizar la tensión entre ese ámbito estructural y las exigencias de inmediatez a las que remite la injusticia, sin asignarles a las iniciativas de responsabilidad un sentido imaginario sino insertándolas en la experiencia de lo real, lo cual le obliga a estar ella misma muy presente y atenta a esa realidad. La tendencia de la universidad no siempre ha reconocido el valor de esta experiencia.

\section{RASGOS DE LAS EXPRESIONES QUE LA PROMO- CIÓN DE LA RESPONSABILIDAD ADQUIERE EN LAS UNIVERSIDADES JESUITAS}

El enfoque de responsabilidad que promueven las universidades jesuitas, de acuerdo a su identidad y tradición, está basado, tal y como hemos señalado, en la noción de justicia solidaria. Este es un punto cen- 
tral para analizar las distintas iniciativas que impulsan para concretarlo e integrarlo en la realidad de sus centros universitarios. El objetivo de este apartado no es enumerar pormenorizadamente cada una de ellas ${ }^{4}$, sino tan solo destacar brevemente, y sin ser exhaustiva, algunos de los rasgos que esa promoción de la responsabilidad adquiere a través de ellas. A mi juicio, son rasgos que denotan una peculiar sensibilidad y aproximación al problema de las injusticias en todos sus ámbitos de actuación cuyos contornos he tratado de perfilar en el epígrafe anterior.

\subsection{En el ámbito educativo, la misión de las univer- sidades jesuitas está orientada a la formación de personas conscientes, competentes, compasivas... y comprometidas}

La formación de ese compromiso está estrechamente relacionada en las universidades jesuitas con la educación de la ineludible dimensión intersubjetiva y social de la responsabilidad. Un sentido de la responsabilidad que se "aprende" únicamente cuando su sentido más profundo aparece encarnado en circunstancias concretas y en contextos significativos; es decir, cuando tiene lugar a través de experiencias de lo real. De ahí que para trabajar su aprendizaje se aborde desde prácticas tanto curriculares como extracurriculares que permiten poner de manifiesto elementos o dimensiones de la responsabilidad que puedan decir algo concreto a los estudiantes. Adquirir esa capacidad de sentir y de pensar, exige, entre otras cosas, imaginación narrativa.

"Esto significa capacidad de pensar cómo sería estar en el lugar de la otra persona, ser un lector inteligente de la historia de esa persona y comprender las emociones, deseos y anhelos que alguien así pudiera experimentar. La imaginación narrativa no carece de sentido crítico (...) Este primer paso de entender el mundo desde el punto de vista del otro es esencial para cualquier juicio responsable. Es preciso descifrar mediante la imaginación el significado de lo que expresa el discurso de esa otra persona, la importancia de lo que expresa en el contexto de su historia vital y de su mundo" (Nussbaum, 2005, p. 30)

Despertar la atención ética de los estudiantes y una determinada educación del asombro que permita recrear la realidad se convierte, de esta manera, en una de las aspiraciones del proyecto universitario jesuita. La capacidad de análisis de la realidad desde las claves de la justicia solidaria busca además profundizar en el alcance ético que tienen las distintas formas de organización de nuestra sociedad para la vida de las personas.
Otro bloque de actividades formativas que se promueven en el marco de este enfoque de responsabilidad, está orientado precisamente a favorecer el reconocimiento de nuestra responsabilidad individual y colectiva ante los retos que la realidad social nos plantea. Estas iniciativas persiguen también avanzar hacia mayores niveles de madurez ética de los estudiantes poniendo el foco en los más fragilizados. En definitiva, se trata de aprender a dejarse cargar por la realidad $^{5}$. En este sentido, iniciativas encaminadas a la educación acerca de lo común, la educación cívica o la participación social buscan favorecer que los estudiantes sean capaces de identificar cuáles son los bienes (de justicia y relacionales) que se protegen y cuál el sentido ético inherente a cada esfera de acción social. Los ciudadanos que cultivan su humanidad, nos sigue recordando Nussbaum, necesitan "la capacidad de verse a sí mismos no solo como ciudadanos pertenecientes a alguna región o grupo, sino también, y sobre todo, como seres humanos vinculados a los demás seres humanos por los lazos de reconocimiento y mutua preocupación. Cultivar nuestra humanidad en un mundo complejo e interconectado implica entender cómo es que las necesidades y objetivos comunes pueden darse en forma distinta en otras circunstancias" (Nussbaum, 2005, p. 29) Es por ello que muchas de las acciones formativas orientadas al logro de este objetivo estén relacionadas en las universidades jesuitas con un tipo de aprendizaje que trabaja distintas dimensiones: la profundidad del conocimiento, la sensibilidad ética, una visión holística de la realidad, la participación, etc.

Otro de los rasgos que comparten muchas de las iniciativas formativas promovidas por las universidades jesuitas, con la cautela de la necesaria adecuación a la realidad propia que exige en cada caso, tiene que ver con procesos de deliberación, argumentación ética y pensamiento crítico pensados para educar la creatividad ética, la capacidad de analizar la calidad normativa de las razones que avalan nuestras decisiones y el alcance colectivo que tienen. Experimentos de lo que podría denominarse una "vida examinada" que "exige el desarrollo de la habilidad de razonar lógicamente, de poner a prueba lo que uno lee o dice desde el punto de vista de la solidez del razonamiento, de la exactitud de los hechos y la precisión del juicio". (Nussbaum, 2005, p. 28). Es así como aspectos tales como, entre otros, la capacidad de reconocer y valorar los aspectos normativos, la importancia de dar y darse razones, el marco de derechos y deberes inherentes al ejercicio de la ciudadanía; la capacidad de hacer una estimativa de las consecuencias, sope- 
sar deliberada y reflexivamente, y deliberar sobre la justeza de las razones, adquieren especial relevancia en esa "educación de la responsabilidad basada en la justicia solidaria".

4.2. En el ámbito de la investigación y la transferencia de conocimiento, la misión de las universidades jesuitas asume la opción preferencial por los pobres, de profunda raigambre evangélica, como una dimensión transversal

Los rasgos de la identidad y misión jesuitas en la investigación tienen como referencia el compromiso que asume con la misión fe-justicia. Un compromiso que exige el desarrollo de un conocimiento profundo, riguroso y sapiencial de la realidad. Un conocimiento experiencial, sensible y sintético. Una investigación de frontera, que tiende puentes con las culturas de su tiempo. Una investigación situada, encarnada, cuyos rasgos distintivos vienen definidos por la pertinencia, la interdisciplinariedad, la vocación por la transformación, la incidencia, la síntesis, la implicación afectiva, el reconocimiento y la cercanía con las personas empobrecidas, el compromiso con las corrientes de vida y liberación, la lucha contra la exclusión y las estructuras de pecado. Es una investigación, en definitiva, que implica un magis. Su principal reto consiste en hacerse presente y significativa en un contexto y en una cultura hegemónica que no aprecia ni valora ninguno de esos rasgos.

Existen además otros rasgos que dan cuenta de la raigambre jesuita con la que se aspira a promoverse la investigación y la transferencia de conocimiento en sus centros universitarios: una investigación pertinente: obligada a estrechar los puentes existentes entre los que producen y entre los que se apropian del conocimiento. Una investigación con sentido: obligada a enfrentar problemas sociales importantes, que está situada en contextos concretos, que es interdisciplinaria, que es relevante, que se deja afectar por la realidad y tiene incidencia política. Una investigación situada: obligada a hablar desde un lugar concreto (desde los pobres y para los pobres), y responder a una mirada concreta de la realidad que se ocupa y preocupa de problemas comunes y tiene una vocación transformadora, ya que espera no dejar al mundo tal y como estaba. Una investigación que se pregunta críticamente por los espacios institucionales que abre para favorecer su ejercicio: obligada, por tanto, a asumir la importancia de ser consciente de los posibles yugos que ponen en peligro el desarrollo de su función social; a evaluar la incidencia que tiene en la agenda social, económica y política del territorio; a articular su lugar social en coordinación con la red de actores y agentes del territorio donde se inserta; a rendir cuentas sobre la significatividad en la esfera pública de sus resultados; y a dar una respuesta ampliada a lo que exigen de una universidad los problemas de la sociedad.

Una investigación, en definitiva, que favorece aprendizajes de micropolítica y que necesita construirse en colaboración con el sector social, con otras organizaciones, en red, y con un carácter internacional. Una investigación, en palabras de Adolfo Nicolás, que nos pide asumir también la capacidad de agencia en la transformación de la realidad de los seres humanos. Capacidad que supone poder incidir en el mundo, ser su co-creador, y colaborar en el "servicio de la fe y la promoción de la justicia" (véase Profundidad, universalidad y ministerio intelectual).

\subsection{En el ámbito de la proyección social, la misión de las universidades jesuitas está orientada a la trans- formación social}

Este es un rasgo que tiene un carácter finalista ya que apunta hacia un elemento nuclear de la razón de ser de una universidad jesuita, comprometida con la transformación de las estructuras de convivencia que traen consigo relaciones de injusticia. Esa vocación social transformadora está presente en el corazón mismo de su misión universitaria. Su identidad, todo lo que ella hace y es, está motivado por esa reconocida vocación social y orientado a ese objetivo transformador. Otra cosa es la manera en la que cada universidad responde a esa vocación y qué estrategias planifica para conseguir ese objetivo, ya que no podemos olvidar, como se ha repetido anteriormente, que no todas las universidades jesuitas son iguales ni tienen la misma estructura, dimensión o capacidad. Incluso las variables culturales y ambientales tienen una incidencia notable. Por eso, será preciso definir la naturaleza y peculiaridades de las universidades y plantear transiciones posibles en cada una de ellas que les hagan avanzar en esa dirección.

En cualquier caso, una universidad que se plantea como parte de su misión la transformación de las estructuras de injusticia de nuestra sociedad, tiene que estar situada de una manera muy concreta en esa realidad. Debe conocerla, saber identificar cuáles son las urgencias a la que debe atender y quienes deben ser sus interlocutores. Debe ser también una universidad reconocida por ese mismo entorno por su capacidad para llevar a cabo esa tarea de transformación. Necesita legitimidad para conseguirlo. Y el primer paso que 
hay que dar para obtener dicha legitimidad pasa por aceptar que no solo está preparada para ello, sino que hace suyo ese compromiso de cargar con la realidad para tratar de transformarla.

Su vocación por la transformación social interpela a la Universidad con retos y preguntas acerca de la necesidad de transformar sus propias estructuras para llevar a cabo esa tarea de promoción de la justicia social. También pone de manifiesto las dificultades y resistencias para mantener la identidad jesuita en un contexto erosionado que no concede nada de valor a las identidades densas de algunas comunidades.

\section{CONCLUSIÓN}

En este artículo hemos analizado la noción de responsabilidad política basada en la idea de justicia solidaria. Nuestro objetivo ha sido poner de relieve la manera en la que está presente en la identidad y misión compartida de las universidades jesuitas. Esto nos ha permitido también mostrar cómo es un enfoque que está ampliamente aceptado y asentado. Remarcando los retos a los que debe hacer frente para concretar ese compromiso y señalando algunos de los rasgos sobre los que construye algunos de los proyectos universitarios en el ámbito de la docencia y la investigación, hemos podido visibilizar finalmente la preocupación, los esfuerzos y algunos enfoques orientados a realizarlos en la práctica eficazmente.

\section{AGRADECIMIENTOS}

Este trabajo se inscribe en el marco del equipo de investigación Retos socioculturales y derechos humanos en un mundo en transformación del Instituto de Derechos Humanos Pedro Arrupe de la Universidad de Deusto, financiado por el Departamento de Educación, Universidades e Investigación del Gobierno Vasco-Eusko Jaurlaritza [Ref. IT713-13]. Asimismo, se ha beneficiado de los comentarios del Grupo de Homólogos de Responsabilidad Social Universitaria de la Red de Universidades Confiadas a la Compañía de Jesús (AUSJAL) en 13 países de América Latina, con el que la autora colabora desde 2010.

\section{NOTAS}

1. Aunque es posible acudir a distintos ejemplos que manifiesten el interés por esta responsabilidad hacia el mundo, rescatamos brevemente dos llamadas a la responsabilidad que son paradigmáticas por el significado que adquieren en el marco de esta reflexión. La primera de ellas data de enero de 2009. Fue pronunciada durante la ceremonia de posesión a la presidencia de Estados Unidos por Barack Obama en la que destacó su llamada a la responsabilidad para afrontar los retos a los que se enfrenta el mundo entero. Esta, en cualquier caso, no era la primera vez en la que se apelaba a la necesidad de restaurar en la esfera pública el valor de la responsabilidad, advirtiendo sobre la no sostenibilidad del mercado si sus reglas siguen dándole la espalda. Las palabras pronunciadas por Kofi Annan en un discurso ante el Foro Económico Mundial de Davos en enero de 1999, en la presentación de una iniciativa mundial, el Global Compact, proponían fomentar la responsabilidad cívica de las empresas para que éstas contribuyan a responder a los retos que plantea la globalización y ayuden a hacer realidad una economía mundial más sostenible e inclusiva. Esta iniciativa invitaba a colaborar a las empresas con los Organismos de las Naciones Unidas, las organizaciones laborales y la sociedad civil para promover, con un carácter universal, principios sociales y medioambientales que facilitasen a las empresas, principalmente a las compañías multinacionales, elementos para la gestión de su responsabilidad en un escenario de economía global, y claves para el seguimiento de dicha gestión por parte de los poderes públicos, la sociedad civil y la ciudadanía en general.

2. La Conferencia de Rectores de las Universidades Españolas (CRUE) y la Comisión Técnica de la Estrategia Universidad 2015 del Ministerio de Educación de España fueron en su momento un referente importante para impulsar y desarrollar en las universidades españolas algunas iniciativas de responsabilidad social universitaria, particularmente relacionadas con el impulso del desarrollo sostenible.
3. La Congregación General es el máximo órgano legislativo de la Compañía de Jesús. Hasta el momento ha celebrado 36 Congregaciones Generales en toda su historia. De las mismas se publican los "decretos" que recogen las decisiones adoptadas y ofrecen orientaciones sobre las cuestiones tratadas en cada una de ellas.

4. Las iniciativas que dan cuenta de estos rasgos son innumerables. Una excelente síntesis con ejemplos concretos se encuentra en Álvarez, 2014.

5. Jon Sobrino (2007) nos recuerda las tres dimensiones de la estructura formal de la inteligencia a la que se refería Ignacio Ellacuría: "hacerse cargo de la realidad" (dimensión intelectiva), "cargar con la realidad" (dimensión ética), y "encargarse de la realidad" (dimensión práxica). A estas tres, Sobrino añade una cuarta dimensión: "dejarse cargar por la realidad" que remite a la influencia que tiene la realidad, o ciertos elementos de la misma, en nuestra manera de estar en el mundo. 


\section{BIBLIOGRAFÍA}

Álvarez, P. (ed.). (2014). La promoción de la justicia en las universidades de la Compañía. Promotio lustitiae, 116. [En línea]. Disponible en http://www.unijes. net/?wpfb_dl=45

Álvarez de los Mozos, P. (2009). La investigación social en el horizonte de la misión de la Compañía de Jesús. Revista de Fomento Social, 64, pp. 49-78. Disponible en http://fundacionellacuria.org/ actualidad/la-investigacion-social

Arendt, H. (2007). Responsabilidad y Juicio. Barcelona: Paidós.

De la Cuesta González, M., de la Cruz Ayuso, C. y Rodríguez Fernández, J. M. (coords.). (2010). Responsabilidad Social Universitaria. La Coruña: Netbiblo. Disponible en http://consellosocial.udc. es/uploadedFiles/CSUDC.b7psr/fileManager/Responsabilidad\%20social\%20 universitaria.pdf

De la Cruz Ayuso, C. y Sasia Santos, P. (2008). La responsabilidad de la universidad en el proyecto de construcción de una sociedad. Educación Superior y Sociedad (Nueva época), año 13, 2, pp. 17-53.

De la Cruz Ayuso, C. (2010). La responsabilidad de la universidad en la sociedad que la acoge: ¿complementariedad o antagonismo? En: De la Cuesta González, M., de la Cruz Ayuso, C. y Rodríguez Fernández, J. M. (coords.). (2010). Responsabilidad Social Universitaria. La Coruña: Netbiblo, pp. 25-45.

De la Cruz Ayuso, C. (2011). Reflexiones sobre la promoción de la responsabilidad en las instituciones de educación superior: retos, limitaciones y oportunidades. Pensamiento Universitario, 21, pp. 61-74.

De la Cruz, C. (2012). El lugar social de la universidad: algunas claves para pensar sobre su responsabilidad social. En: Villa Sánchez, A. (ed.). Avances en la innovación universitaria. Tejiendo el compromiso con las universidades. Bilbao: Mensajero.

De la Cruz Ayuso, C. (2013). Los sentidos de la responsabilidad desde el prisma de la justicia: ¿quién es responsable de las injusticias estructurales de nuestra sociedad? Sal Terrae, 101, pp. 663-676.

Derrida, J. (2002). Universidad sin condición. Madrid: Trotta.

García Vázquez, J. M. (coord.). (2001). La universidad en el comienzo de si- glo. Una respuesta entre el pragmatismo y la utopía. Madrid: Libros de la Catarata.

González Fabre, R. (2012). Operativizar la justicia en el siglo XXI. Promotio lustitiae, 108, pp. 29-36. Disponible en http://www.raulgf.com/archivos/GonzalezFabreR2012PI.pdf

Greene, T. (2012). Observaciones sobre el apostolado social, la justicia y los decretos de las Congregaciones 31 a la 35. Promotio Iustitiae, 108, pp. 6-14. Disponible en http://www.sjweb.info/ uploads/pdf/2_PJ/A9_3.pdf

Ibañez, F. (2012). Caracterizando la justicia social. Promotio lustitiae, 108 , pp. $22-$ 28. Disponible en http://www.sjweb. info/uploads/pdf/2_PJ/A14_3.pdf

Jonas, H. (1995). El principio de responsabilidad. Ensayo de una ética para la civilización tecnológica. Barcelona: Herder.

Kolvenbach, P. H. (2009). Lección inaugural en la Universidad San Alberto Hurtado. Santiago de Chile, 1 de Mayo de 2006. En Asociación de Colegios Jesuitas de Colombia (ACODESI). EI P. Peter-Hans Kolvenbach, S. J. y la educación. 1983-2007 (Selección de escritos), pp. 243-252. [En línea]. Disponible en http://www.acodesi.org.co/es/ images/Publicaciones/pdf_libros/ El-P.-Peter-Hans-Kolvenbach,-S.J.-y-laEducacion-1983-2007.pdf

Muguerza Carpintier, J. (2002). ¿Convicciones y/o responsabilidades? (Tres perspectivas de la ética en el Siglo XXI). Laguna. Revista de Filosofía, 11, pp. 23-46.

Nussbaum, M. (2005). El cultivo de la humanidad. Una defensa clásica de la reforma en la educación liberal. Barcelona: Paidós.

Ovejero, F. (2012) La crisis: una mirada moral. Claves de razón práctica, 224, pp.100-115.

Singer, P. (1993). Practical Ethics. Cambridge: Cambrige University Press.

Sobrino, J. (2007). Fuera de los pobres no hay salvación. Pequeños ensayos utópico-proféticos. Madrid: Trotta.

Young, I. M. (2011). Responsabilidad por la justicia. Madrid: Morata. https://doi.org/10.1093/acprof:o so/9780195392388.001.0001
Vallaeys, F., De la Cruz, C. y Sasia, P. M. (2009). Responsabilidad social universitaria: Manual de primeros pasos. México: McGraw-Hill Interamericana. Disponible en http://planeacion.unach. mx/images/Insumos\%20PDI-2030/Manual_Responsabilidad_Social.pdf

\section{Recursos de Internet}

Conferencia Mundial sobre la Educación Superior - 2009: La nueva dinámica de la educación superior y la investigación para el cambio social y el desarrollo. (Sede de la UNESCO. Paris, 5-8 de julio de 2009). Comunicado (8 de julio de 2009). [En línea]. Disponible en: http://www.unesco.org/education/ WCHE2009/comunicado_es.pdf

La responsabilidad social de la universidad y el desarrollo sostenible. Documento elaborado por la Comisión Técnica de la Estrategia Universidad 2015. Ministerio de Educación. Secretaria General de Universidades, 2011. [En línea]. Disponible en https://sede.educacion.gob. es/publiventa/descarga.action?f_codigo_agc=14925_19

Nicolás, A. Los Antiguos Alumnos de la Compañía de Jesús y su Responsabilidad Social: la búsqueda de un mejor futuro para la Humanidad. ¿Qué significa ser creyente hoy? VIII Congreso Mundial de la Unión Mundial de Antiguos Alumnos de la Compañía de Jesús. Medellín. 15 de Agosto de 2013. [En línea]. Disponible en: http://www.sjweb.info/ documents/ansj/130815_Medellin_8_ Congreso_Antiguos_Alumnos.pdf

Nicolás, A. Profundidad, universalidad y ministerio intelectual. Retos para la educación superior jesuita hoy. [En línea]. Disponible en http://www.sjweb.info/documents/ansj/100423_Mexico_ESP.pdf

\section{Otras fuentes}

Compañía de Jesús. Congregación General 32. Madrid: Razón y Fe, 1975. Disponible en http://www.sjweb.info/sjs/documents/CG32_D2_esp.pdf

Compañía de Jesús. Congregación General 33. Bilbao: Mensajero, 1984.

Compañía de Jesús. Congregación General 34. Un proyecto para el siglo XXI: selección de textos de la Congregación General 34 de la Compañía de Jesús. Madrid: 1997. Disponible en http://www.sjweb. info/documents/education/CG34_ D17_SPA.pdf 
Compañía de Jesús. Congregación General 35. Bilbao-Santander: Mensajero-Sal Terrae, 2008. Disponible en http://www. sjweb.info/35/documents/Decretos.pdf 